Landslides (2019) 16:1619-1620 DOI 10.1007/s10346-019-01215-6 Received: 27 January 2019 Accepted: 28 May 2019 Published online: 8 June 2019 (c) Springer-Verlag GmbH Germany part of Springer Nature 2019
Matjaž Mikoš

\section{Peter T. Bobrowsky and Brian Marker: Encyclopedia of Engineering Geology, Springer Nature Switzerland, AG 2018, 978 p.}

The Springer Encyclopedia of Engineering Geology (Bobrowsky and Marker 2018) addresses the multidisciplinary topic of engineering geology and the environment. As such, it is of interest for the field of landslide risk reduction. It is a part of the Encyclopedia of Earth Sciences Series, a Springer Book Series covering all main areas in Earth Sciences. The Earth Sciences Series started publishing volumes in 1968, and the Encyclopedia of Engineering Geology, published as First Online on August 1, 2018, is the last volume out of 42 volumes published so far (https://link.springer.com/bookseries/5898). Several volumes in this Springer Encyclopedia of Earth Sciences Series is of interest for landslide researchers, geologists, engineers, academia and others involved into landslide risk reduction: in addition to the Encyclopedia of Engineering Geology also the Encyclopedia of Remote Sensing (Njoku 2014), and the Encyclopedia of Natural Hazards (Bobrowsky 2013). It is worth mentioning that the Springer Encyclopedia of Engineering Geology is available on the web in two electronic forms, as a static electronic book (2018 Edition; https:// link.springer.com/referencework/10.1007/978-3-319-73568-9) and as living/updatable eBook (Living Edition; https:/link.springer.com/ referencework/10.1007/978-3-319-12127-7).

Since all of these Springer encyclopaedias are not only part of the aforementioned Springer book series in earth sciences, but their e-versions are also included into the eBook package Earth and Environmental Science, their reach out to the readers can be estimated to be noticeable. Until mid-April 2019, using Bookmetrix data, the Encyclopedia of Natural Hazards (published in 2013) got $84 \mathrm{k}$ downloads and 194 citations, the Encyclopedia of Remote Sensing (published in 2014) got $45 \mathrm{k}$ downloads and 58 citations, and the latest Encyclopedia of Engineering Geology (published in 2018) has already got $3.3 \mathrm{k}$ downloads and waits is waiting for getting first citations; its living/updatable eBook got so far $16 \mathrm{k}$ downloads and 7 citations, since the entries have been published as First Online as accepted, some as early as in late 2016.

The Encyclopedia of Natural Hazards was one of the 343 books in the Springer's Earth and Environmental Science eBook Collection published in 2013 and with 194 citations so far is the second best cited volume from 2013 in this collection. Looking back at the scientometric data of the other Springer encyclopaedias, we may expect for the last one in the Earth Sciences Series, the Encyclopedia of Engineering Geology, to follow the rule.

Looking at the Encyclopedia of Natural Hazards, the vast majority of its 194 citations were given to its single chapters (entries in the encyclopaedia) and not to the entire volume. This confirms the practical value of such encyclopaedias that lies in their single entries and I understand that nobody reads the whole encyclopaedia as a book. For academics, the fact that books from the Springer Encyclopedia of Earth Sciences Series are covered by SCOPUS, is of benefit. Of course, encyclopaedias are far more read than cited as a primary source (such as an original research paper or a review paper), and rather used as a state-of-the-art reference volume.
All Springer encyclopaedias are enriched by illustrations. The Encyclopedia of Engineering Geology has $140 \mathrm{~b} / \mathrm{w}$ illustrations and 491 illustrations in colour on 978 pages for 332 entries. One could claim that the list of entries is not exhaustive, but the volume is a comprehensive overview of engineering geology, offering balanced state-of-the-art reference work in this dynamic field of earth sciences. This book was awarded the best Single Volume Reference Award in Science PROSE Award in 2019 by The Association of American Publishers (AAP).

The entries were written by 200 specialists from over 30 countries from all continents-the majority from USA (32 entries), followed by Italy (31), UK (30), Canada (24), Iran (21), ... One fifth of all entries (i.e. 67 out of total 332 entries) are multi-author contributions, the rest are single-author chapters. One would expect the volume to be therefore unbalanced or hard to read across. This is not the case, and the editors are to be congratulated for a well-executed editorial work. The volume was technically well prepared by giving precise instructions to all authors how to write their contributions. Hence, entries in the encyclopaedia are sharing the same structure and format. The entries are of the three different lengths, defined by the editors: (a) major discipline subjects with about 5000 to 9000 words, up to 10 tables/figures and up to 20 references; (b) summaries of important topics or case studies with about 1000 to 3000 words, up to 5 tables/figures, and up to 10 references; (c) definitions and mini biographies with up to 500 words, maximum 1 table/figure, and up to 5 references. This approach and the predefined structure of the entries help to improve readability of this multi-author work. Other entries then definitions (type c) have the following structure: title, synonyms, definition, main entry text, summary or conclusions, cross-references, and bibliography.

The covered major subjects from engineering geology (entries of type a) of interest for the landslide community are among others: Geohazards (pp. 381-389), Hazard Assessment (pp. 454478), Hazard Mapping (pp. 479-487), Mass Movement (pp. 597604), Monitoring (pp. 669-676), Risk Mapping (pp. 761-769), and Soil Laboratory Tests (pp. 853-871). The references at the end of entries are balanced between classical works and newest literature in the field of engineering geology. It is also of interest for the readers of the journal Landslides to be stressed that among the authors several ICL members can be found, from Canada, Czech Republic, Italy, Russia, Slovakia, Slovenia, and USA. One of the Editors (Peter T. Bobrowsky) is also the President Elect of the International Consortium on Landslides (ICL) for the period 2018-2020.

The Springer Encyclopedia of Engineering Geology (2018 Edition) is to be welcomed and used among the experts in the field of landslide risk reduction, as well as a textbook for undergraduate students in geological sciences and civil engineering. This is even truer for its updatable living edition that should take into account 
new developments in the fast-growing field of knowledge and expertise in engineering geology.

Acknowledgements

The author would like to thank Fabio Luino and another anonymous reviewer for thoughtful comments on the original manuscript.

\section{References}

Bobrowsky PT (ed) (2013) Encyclopedia of Natural Hazards. Springer, Dordrecht, pp 1135-332 entries
Bobrowsky PT, Marker B (eds) (2018) Encyclopedia of Engineering Geology. Springer, Cham, pp 978-284 entries

Njoku EG (ed) (2014) Encyclopedia of Remote Sensing. Springer, New York, pp 939-170 entries

M. Mikoš (-

Faculty of Civil and Geodetic Engineering,

University of Ljubljana,

Jamova cesta 2, SI-1000, Ljubljana, Slovenia

Email: matjaz.mikos@fgg.uni-lj.si 